\title{
O MITO DO ORIENTE NO IMAGINÁRIO BRASILEIRO
}

\author{
Ana Lúcia Liberato Tettamanzy
}

RESUMO: Throughout the years, the Orient has been a mythical place to Portugal and Brazil, on which they reflect, albeit imaginatively, the dilemma of their own identities. In O Mandarim, Eça de Queiroz dramatizes the mediocrity of Portuguese life through Teodoro, who, while embarking on a voyage in search of a misterious mandarin, ends up discovering his true self. In the short story Academia do Sião, Machado de Assis creates a bizarre plot, dealing with soul exchanges and corruption in a grandiose Chinese Kingdom. Thus, from a luso-brazilian perspective, the Orient seems to stand for both the obscurity and the wonder of human condition.

PALAVRAS-CHAVE: mito, literatura luso-brasileira, identidade, Eça de Queiroz, Machado de Assis

Num sentido amplo, o mito é entendido como uma narrativa que atende a uma coletividade. Sua natureza tende a ser fabulosa, visto que há a intervenção de construções imaginárias e que, em geral, suas personagens são seres extraordinários, deuses ou heróis. Entretanto, o conceito de mito evoluiu muito a partir desta acepção, aproximando-se da filosofia e vindo a constituir-se como uma ciência. Modernamente, através dos estudos do imaginário, cria-se um campo comum de investigações para diversas disciplinas. De qualquer maneira, pode-se entender o mito como a resposta a uma pergunta coletiva, reveladora da necessidade de preenchimento de um espaço vazio.

No estudo Do Mythos ao Mito, Victor Jabouille discute a definição de mito de forma ampla, apontando aspectos que incluem não apenas a narrativa, mas também as situações imaginárias que, por serem redundantes, acompanham o que pode ser chamado de alma de um determinado povo. Com este entendimento, dedica um capítulo de seu estudo à constituição de uma "mitologia portuguesa", em que demarca, inicialmente, dois grandes grupos: a corrente cultural e crítica, que marca o declínio da convicção patriótica em termos passadistas, caracterizada pela presença dos estrangeirados; e a corrente do auto-convencimento cultural e patriótico, que defende valores nacionais adjacentes à idéia de Quinto Império, agrupando autores de fundo saudosista. Este grupo, segundo o autor, tem origem num dos valores mais expressi-

Ana Lúcia Liberato Tettamanzy é professora da UNISINOS. 
vos na definição do ser português, o sentimento da saudade, misto de desejo e dor, gerando duas atitudes opostas. Uma reflete a saudade do período áureo e glorioso, que acaba por revelar-se um complexo de inferioridade na atitude de imitação aos grandes "lá de fora". A outra sugere que se resgate a tradição perdida através de várias atitudes, como por exemplo, de um sebastianismo racional (JABOUILLE, 1993, p. 65-9).

Há também o eixo correspondente à vocação teleológica de Portugal, envolvendo o país numa razão messiânica, que o predestina a "tomar conta do mundo", como já dissera padre Antonio Vieira sobre os portugueses: "Vós sois a luz do mundo"(Idem, Ib., p.70). Sobre o caráter do português, Jabouille enfatiza, ainda, a união do aspecto místico e do fundo prático, o que pode explicar a sua enorme capacidade de adaptação e assimilação (Idem,Ib., p.73). Com o episódio da Revolução dos Cravos, que pôs fim à ditadura de Salazar em 75, restou ao português defrontarse com o vazio deixado pelo mito expansionista e defrontar-se com sua situação num mundo em acelerada metamorfose. Por fim, numa espécie de grupos de mitos menores, o autor aponta o sentimento de pequenez e de marginalidade, a nostalgia do impossível e a espera do salvador escondido, muitas vezes materializado no Sebastianismo (Idem, Ib., p.75-7).

A complexidade desse imaginário português tem, em boa parte, origem na época dos descobrimentos, em que Portugal venceu os oceanos e abriu o caminho para os mistérios do Oriente, inserindo fortemente a idéia de alteridade no imaginário do Ocidente. A grandiosidade desses eventos, como uma sombra, desencadeou um processo mítico que se prolonga por várias gerações literárias. O ensaísta Eduardo Lourenço assim analisa as conseqüências - ainda presentes - do irrealismo na imagem que os portugueses fazem de si mesmos:

"Acontece, todavia, que mesmo na hora solar da nossa afirmação histórica, essa grandeza era, concretamente, uma ficção. Nós éramos grandes, dessa grandeza que os outros percebem de fora e por isso integra ou representa a mais vasta consciência da aventura humana, mas éramos grande longe, fora de nós, no Oriente de sonho ou num Ocidente impensado ainda." (LOURENÇ, 1992, p.19. Grifo do autor).

Álvaro Machado contribui para a discussão das origens da problemática a respeito da auto-imagem lusitana. Escolhe três entre os cronistas e historiadores das navegações para ilustrar como o Oriente vem a constituir um mito na literatura portuguesa. João de Barros, apesar de ter viajado pouco, era o cronista oficial encarregado por D. João II de tratar das "cousas das partes do Oriente" (MACHADO DE ASSIS, 1983, p.29). Seu embasamento, através de coleções de manuscritos orientais, misturou-se a uma laboriosa imaginação. Ainda assim, o historiador reconheceu lucidamente que, apesar de todo o heroísmo dos portugueses, o Oriente tornara-se algo incontrolável e sua estratégia político-econômica não fora suficiente para conservar as conquistas de além-mar (Idem, Ib., p.33). Diogo do Couto tomou parte como soldado de várias campanhas no Oriente, tendo, inclusive, tornado-se amigo de Camões. Com um tom coloquial (diferente, portanto, do tom de João de Barros), Couto divide a Índia que conhecera em duas: a do passado é representada por Afonso de Albuquerque e pelos conquistadores impolutos, que, indiferentes à riqueza, relegaram o comércio a um segundo plano; a do presente, isto é, a Índia do seu tempo - fins do século XVI e princípios do XVII - era mercantil e corrupta, o que conduz a uma decadência interpretada como divina, expressa em termos de mitologia bíblica, misturada com a mitologia dos descobrimentos. Para o cronista, como explica Machado, a Índia assume o aspecto de um perfeito paraíso perdido, contrastando a pureza da terra com a impureza dos homens, num processo em que a ficção vai substituindo a crônica histó- 
rica para compensar a degradação e a frustração experimentadas nessas terras longínquas (Idem, Ib., p.43-4). Por fim, com Fernão Mendes Pinto (1510-1583), o autor de Peregrinação, a experiência do Oriente torna-se mais vasta, não só por não se restringir mais à Índia, mas pelo espírito peregrino e aventureiro de Fernão, que percorreu os reinos da China e do Japão. O Oriente desperta neste português não apenas os sentidos e a utopia, estimulados pela abundância de riquezas naturais que observou ou pela grandiosidade das culturas com que teve contato. Com o reconhecimento da estreiteza de sua pátria e de si mesmo, Fernão afasta-se tanto da exaltação retórica do longínquo (como fizera João de Barros) como do lamento dramático da perda do paraíso (caso de Diogo do Couto). Se, conforme Álvaro Machado, de um lado, Fernão deu origem à mítica visão do Oriente, precursora de um orientalismo exótico predominantemente descritivo que será moda no século XIX, de outro, transformou a raiz mítica nacionalista e a fascinação pelo longínquo numa sátira não só da ação dos portugueses no Oriente, mas de toda a civilização ocidental (Idem, Ib., p.46-9).

É nesse contexto de fantasia exótica que Álvaro Machado enquadra Eça de Queiroz (1845-1900), que utiliza em O Mandarim (primeira edição em livro em 1881, e primeira publicação no Diário de Portugal em 1880) o culto orientalista em oposição ao realismo programático de suas obras anteriores, $O$ crime do padre Amaro (1876) e O primo Basilio (1878). O ensaísta explica ainda que Eça recorre à fantasia do exotismo oriental em moda para melhor caricaturar o espírito português (percebido como rústico e bucólico), ou como pretexto para exercícios de estilo (longas descrições fortemente adjetivadas), o que corresponderia, a seu ver, a uma influểncia de Baudelaire na busca de um lugar de luxo e voluptuosidade (Idem,Ib., p.85-7).

De fato, o caráter de Eça é bastante peculiar. Tendo vivido o final do oitocentismo, o escritor viu frustrarem-se as ilusões da geração de 70, que preconizava a modernização e idéias revolucionárias dos socialistas e dos republicanos num país pouco industrializado e arruinado por uma crise financeira, política e moral. Pode-se afirmar, de acordo com José Antonio Seabra, que a fase inicial, onde misturam-se invocações líricas, meditações metafísicas, traços místicos e religiosos (com influências de Baudelaire, Poe, Victor Hugo e Nerval) revela um peculiar romantismo, do qual participam o satanismo e o panteísmo, constituindo uma antecipação do simbolismo. Na fase seguinte, de reação contra o romantismo através do realismo, o autor propunha-se a observar e condenar a sociedade através de romances sociais. Entretanto, sem esquecer as inclinações fantásticas e fantasiosas com viés moralizante e satírico, nem o gosto pelas notas líricas e pelo apuro da escrita, Eça desemboca no terceiro momento, o da apoteose do romance em Os Maias, no qual a tragédia e a comédia humanas têm lugar. Este período coincide com seus últimos anos de vida em Paris como Cônsul de Portugal, descrente dos novos "ismos" que surgiam em profusão na metrópole francesa, mas identificado com o espírito de decadentismo finissecular (SEABRA, 1995, p.15-24). Nesse sentido, O Mandarim, produzido na fase intermediária da obra queirosiana, revela uma tendência permanente no escritor, o pendor para o fantástico e para o sardônico, não sem certa amargura.

Cabe agora mencionar a relação com Machado de Assis. O episódio mais conhecido entre os dois, provavelmente, envolve as severas críticas que o brasileiro teceu aos romances de Eça pelo exagerado cumprimento da cartilha do realismo, o que teria resultado num estilo baixo e em personagens débeis. Sem retomar aqui a polêmica, cabe ressaltar o fato de que havia contato entre as duas obras, o que comprova a repercussão violenta em Portugal à crítica machadiana. $O$ conto que interessa comparar com O Mandarim, intitulado "As academias de Sião", encontra-se no livro Histórias sem data, publicado em 1884. Ora, esta publicação incide no que parte da crítica chamou de segunda fase machadiana, em que o escritor abandona a estética 
romântica em prol da perspectiva realista a partir da publicação do romance Memórias póstumas de Brás Cubas, em 1881. Contudo, assim como em Eça, tal divisão não é tão simples, visto que o caráter grotesco e estranho de muitos textos machadianos rompe com o paradigma da ficção realista. Em relação ao mito do Oriente em terras brasileiras, há que observar que, para Portugal, por muito tempo, também o Brasil havia sido uma Índia exótica e longínqua, mais um "outro" entre tantos com que a Europa veio a ter contato. Conforme explica Silvano Peloso na obra $O$ canto e a memória: história e utopia no imaginário popular brasileiro, os aventureiros que embarcavam para o Brasil traziam, na memória ou em livros amarrados por cordões, as folhas volantes com histórias da literatura popular, notadamente textos de cavalaria (como os Amadises de Gaula), novelas pastoris, narrativas edificantes e livros religiosos, que acabaram por misturar-se ao imaginário das viagens que vinha da Antigüidade clássica, mantendo as últimas sombras da Idade Média nas auroras da Renascença. É desse caldo híbrido que nasce o imaginário na nova terra:

"A tendência em sublinhar os aspectos surpreendentes, incríveis e grotescos de mundos longínquos, em uma época em que os limites entre o normal e o maravilhoso não são definidos, justifica-se também com a exigência de recriar, diante do quadro tradicional do mundo, uma outra realidade extravagante e fabulosa, sobre a qual se projetam exigências e vicissitudes da alma popular. A grande metáfora da viagem se desenvolve sobre dois planos convergentes: ao realismo das várias crônicas se sobrepõe uma paisagem grotesca, contaminada por recordações literárias e ilusões fabulosas. Desse modo, as imagens transmitidas da Antigüidade clássica, com suas maravilhas e prodígios, assumem um significado e uma função novos; mitos e figuras cristalizados por uma longa tradição, através do fascínio do exótico e do módulo geográfico, tornam-se metáfora de outros itinerários em que, entre paródia e travestimentos, abaixamentos e profanações, exprime-se a ânsia de criação de toda uma época." (PELOSO, 1996, p. 49).

Esse fragmento ilustra a mistura de crenças e fantasias nos primeiros viajantes portugueses que vieram ao Brasil. O fato de muitas dessas histórias e tradições permanecerem vivos até hoje, principalmente no interior brasileiro, demonstra que o mito do Oriente é transfigurado no Novo Mundo, onde o fascínio do exótico, como não poderia deixar de ser, é integrado ao cotidiano, assimilado pela cultura popular. A fusão do maravilhoso clássico com o medieval no imaginário proveniente das navegações perpetua-se de forma a constituir um espaço de significação luso-tropical que sugere a chave de leitura para a abordagem dos textos de Eça e Machado.

Em $O$ Mandarim, tem-se a fantástica história de um lisboeta que é visitado pelo Diabo, que lhe promete fortuna se ele concordar em tocar uma campainha, mesmo sabendo que tal atitude resultaria na morte um velho mandarim chinês. Teodoro, assim chamava-se o eleito, indiferente a um distante mandarim que sequer imaginava, faz o que lhe é indicado e enriquece. Após o fastio e a devassidão obtidos com o gozo da infindável fortuna, solitário e melancólico, o entediado milionário viaja à China com a esperança de diminuir sua culpa encontrando os familiares do mandarim e prestando-lhes auxílio. Nessa viagem de auto-descoberta, Teodoro depara-se com um país fascinante: na grandiosidade das muralhas, na multidão de cores e formas de Pequim, dividida rigidamente em bairros nobres e miseráveis, o viajante oitocentista repete o sentimento de admiração que séculos atrás deixara perplexos outros lusitanos como ele, numa espécie de repetição entre doentia e emocionante do passado. "A muralha agora, ao perto, parecia erguer-se aos céus com o horror duma construção bíblica; à sua base apinhava-se uma confusão de barracas, feira exótica, onde rumorejava uma multidão, e a luz de lanternas oscilantes 
cortava já o crepúsculo de vagas manchas cor de sangue; os toldos brancos faziam ao pé do negro muro como um bando de borboletas pousadas" (QUEIROZ, 1996, p.48).

A prosa poética de Eça fica evidente na descrição plástica, calcada nas cores e impressões sensoriais do viajante em êxtase. A presença do misticismo acrescenta um outro aspecto: revela a subjetivização da viagem, agora num plano interno, trazendo à superfície sensações insuspeitas e incontroláveis. Entretanto, ao fascínio junta-se o travo melancólico da alma em penitência:

"Dos quiosques santos saía uma sussurração de cânticos, de nota monótona e triste. Pelos terraços, enormes serpentes, venerandas como deuses, iam-se arrastando, já entorpecidas da friagem. E aqui e além, ao passar, avistávamos budistas decrépitos, secos como pergaminhos e nodosos como raízes, encruzados no chão sob os sicômoros, numa imobilidade de ídolos, contemplando incessantemente o umbigo, à espera da perfeição do Nirvana... (Idem, Ib., p.72)

O olhar sobre a diferença intensifica a crise da personagem. Descrente de tudo, até do amor que conhecera fugazmente com uma russa num quiosque de bambus que cheirava a sândalo, Teodoro trai, por esse amor proibido, o homem que o ajudava a descobrir o paradeiro da família do mandarim. A viagem à perdida região da Manchúria vem a ser um desastre: além de não encontrar a família desejada, é roubado e ferido. Em face do horror em que sua existência transformara-se, o solitário Teodoro amaldiçoa não apenas a própria sorte como a de sua pátria, um Portugal glorioso que não mais existia: "Portugal é uma choldra!" (Idem, Ib., p.64). Nesta fala percebem-se os ecos de um dos mais significativos elementos constitutivos da mitologia lusitana, o saudosismo, capaz de explicar as dificuldades do país em defrontarse, no presente, com o peso de um passado glorioso e insepulto. De maneira semelhante, o mandarim transforma-se numa obsessão doentia a torturar a alma de Teodoro através da visão de uma suave pandorga amarela, cruel metáfora do passado do qual é impossível separar-se.

No desfecho da narrativa, o protagonista, em mais uma repetição do passado, cruza com o Diabo numa rua, implorando para perder os milhões e recuperar a paz. Com a negativa, sua vida transcorre como uma imensa ruína, onde também ressoa o destino da pátria portuguesa. Pouco antes da morte, num diálogo com o leitor evidentemente inspirado em Baudelaire, Teodoro conclui que a natureza humana é má:

"E todavia, ao expirar, consola-me prodigiosamente esta idéia: que do norte ao sul e do oeste a leste, desde a Grande Muralha da Tartária até às ondas do Mar Amarelo, em todo o vasto Império da China, nenhum mandarim ficaria vivo, se tu, tão facilmente como eu, o pudesses suprimir e herdarlhe os milhões, ó leitor, criatura improvisada por Deus, obra má de má argila, meu semelhante e meu irmão!" (Idem, Ib., p.99)

O sarcasmo dessa fala insere o peculiar ponto de vista do autor que, sem aderir a nenhuma corrente da época, provoca um olhar moderno na medida em que alia humor e lucidez na visão do homem como mau. Eça traça um perfil escabroso a fim de refletir sobre o absurdo da existência humana, no que se aproxima da dicção moderna do expressionismo ou do fantástico de um Kafka, ainda que o gosto pelo mistério e a morbidez lembrem o romantismo. O Oriente continua sendo o incômodo espelho a revelar a dimensão oculta, talvez o inconsciente, de um sujeito e de uma nação em choque entre a imagem ideal e a imagem real.

Em Machado tem-se situação semelhante. O enredo do conto escolhido remete ao reino de Sião, que ficou famoso pela sua imponência na antigüidade, sendo referido na Bíblia como sinônimo de Israel, a terra prometida. Embora tenha como 
pano de fundo do enredo um bizarro episódio de natureza fantástica, o teor da narrativa envolve muito mais do que isso: numa atitude alegórica, põe em cena temas comuns na ficção machadiana, como a vaidade humana, os desmandos da ciência, a inversão cômica do alto e do baixo resultando num riso amargo. A trama inicia com a rivalidade das academias locais em busca da teoria que melhor explique a singular natureza de seu rei, Kalaphangko, que possui a índole de uma dama num corpo viril. Numa singular forma de fazer ciência, às custas de pancada e do sangue dos vencidos, o grupo vencedor impõe que existem almas masculinas e almas femininas e que algumas encontram-se nos corpos errados. Essa discussão retoma uma vasta tradição de debates sobre a origem das almas e suas peregrinações, tema que percorre não só o pensamento clássico como a teologia cristã. A mais bela das concubinas, Kinnara, possuidora de alma masculina, tendo em mente deflagrar guerras e grandes negócios no reino, exige que o soberano declare como legítima a doutrina vencedora, a das almas sexuadas. Tal reconhecimento permite que, um tempo depois, a dama execute seu plano ambicioso: diz conhecer uma velha lenda hindu que permite a troca de corpos e almas, sugerindo que a alma do rei transfira-se para o seu corpo e vice-versa.

A troca dá-se no meio de um rio, em atmosfera mística. O outrora festivo e alegre país passa a ter um rei belicoso e autoritário, que, com repressão e batalhas, faz funcionar as instituições e os devedores pagarem. A alma masculina de Kinnara, finalmente num corpo masculino, sente-se à vontade. Planeja, então, eliminar a alma feminina do rei, imersa em devaneios no suave corpo da concubina. Em busca de meios que lhe possibilitem executar o plano, convoca os sábios para conversas individuais. Descobre, então, o que cada um pensava dos demais: seriam todos camelos. Conclui que tal conceito não contempla a verdade sobre os ditos sábios do reino: "os camelos são modestos e eles não; comparam-se ao sol e à lua" (MACHADO DE ASSIS, 1994, p.472). Nesse intervalo, a jovem concubina, em paz com a delicada alma do rei, engravida, o que faz a alma belicosa de Kinnara, que estava no corpo do rei, desistir do seu plano perverso. O final do conto mostra cada uma das duas almas, então restituídas ao respectivo corpo original, contemplando a vinda de um barco magnífico, "adornado de plumas e flâmulas", com os catorze membros da academia cantando em auto-elogio: "Glória a nós, que somos o arroz da ciência e a claridade do mundo" (Idem, Ib., p.473). A essa cena segue o irônico comentário do narrador:

"A bela Kinnara (antigo Kalaphangko) tinha os olhos esbugalhados de espanto. Não podia entender como é que quatorze varões reunidos em academia eram a claridade do mundo, e separadamente uma multidão de camelos. Kalaphangko, consultado por ela, não achou explicação. Se alguém descobrir alguma, pode obsequiar uma das mais graciosas damas do Oriente, mandando-lha em carta fechada, e, para maior segurança, sobrescritada ao nosso cônsul em Xangai, China." (Idem, Ib., p.473)

Como Eça, o conto finaliza com o diálogo provocativo com o leitor. Mais uma vez, tem-se episódios de natureza fantástica: se Teodoro vendera a alma ao diabo, as personagens machadianas trocam de alma. Contudo, sobre esse pano de fundo desenrola-se um veio crítico. Em Eça, ressaltavam o saudosismo português e a melancolia em face de uma grandeza perdida, que a viagem aos confins da misteriosa China não é capaz de amenizar, posto que nem a áurea identidade de Portugal, nem a alma de Teodoro podem ser recuperadas. Mais do que isso, a visão de uma cultura envolvente e plástica propicia o acirramento dos conflitos da personagem, que mergulha no âmago de sua amoralidade e descobre o horror. No caso brasileiro, nas entrelinhas esconde-se a denúncia dos exageros do espírito cientificista, conduzido pelos delírios de progresso indefinido e pelas teorias racistas em voga no século XIX. Reunidos em academias - ou seja, em grupos animados por uma teoria comum e pelo uso da força 
-, os cientistas dizem-se sábios, mas, individualmente, revelam-se precários, invejosos, medíocres e violentos, o que sugere a força coercitiva das instituições, seja o governo, seja a academia. Em ambos os textos, o ambiente mágico e longínquo, de paisagens suaves e exóticas, exerce o papel de contraponto ameno à natureza humana, cuja face perversa e doentia vem à tona. Dessa forma, a recuperação do imaginário do Oriente mostra a permanência de seu significado na cultura luso-brasileira. Mais precisamente, a leitura feita por esses escritores revela uma dimensão interiorizada e uma vivência íntima do estranho na cultura luso-brasileira. Contudo, a diversidade não está mais situada no distante Oriente, transferiu-se para um outro que é parte do mesmo na natureza humana, descoberta em sua misteriosa e obscura condição. Os mares então navegados encontram-se, assim, num Oriente que aguarda cada ser em sua densa noite da memória, projeção dos sonhos e da perplexidade na viagem de descoberta rumo a si mesmo.

\section{BIBLIOGRAFIA}

JABOUILLE, Victor. Do mythos ao mito: uma introdução à problemática da mitologia. Lisboa, Cosmos, 1993.

LOURENÇO, Eduardo. Psicanálise mítica do destino português. In: O labirinto da saudade. Lisboa, Dom Quixote, 1992.

MACHADO, Álvaro Manuel. O mito do Oriente na literatura portuguesa. Lisboa, Bertrand, 1983.

MACHADO DE ASSIS, Joaquim Maria. As Academias de Sião. In: Obras Completas. Rio de Janeiro, Nova Aguilar, 1994. v.2

PELOSO, Silvano. Folhas volantes, navios e aventuras. In: $O$ canto e a memória: história e utopia no imaginário popular brasileiro. São Paulo, Ática, 1996.

QUEIROZ, Eça de. O Mandarim. São Paulo, Paz \& Terra, 1996.

SEABRA, José Augusto. Eça de Queirós e a literatura fin-de-siècle. Revista Arca, Porto Alegre, n.3, p. 15-24, 1995. 